\title{
Kenyamanan Lingkungan Termal Ruang Kuliah (C4) Fakultas Teknik Universitas Ichsan Gorontalo
}

\author{
Indah Sari Zulfiana ${ }^{1^{*}}$ \\ ${ }^{1 *}$ Program Studi Arsitektur Universitas Sains dan Teknologi Jayapura \\ E-mail: indahsarizulfiana@gmail.com
}

\begin{abstract}
Thermal comfort of a lecture hall is needed to support the process of receiving learning by students. This study aims to determine the convenience of the thermal environment in the lecture hall (C4) of the Faculty of Engineering, University of Ichsan Gorontalo using an artificial ventilation system (AC). The questionnaire was distributed to 30 Architectural Engineering students using ASHRAE thermal sensations, reception of thermal conditions and thermal preferences. Simultaneously, field measurements are carried out to determine the air temperature (Ta), relative humidity (RH), Mean Radiant Temperature (MRT) and air velocity (Va). The results showed that 50\% of students chose rather cold on their thermal sensations while 97\% accepted the thermal conditions of the room, and nearly $70 \%$ of students did not want a change in thermal conditions in the room.
\end{abstract}

Keywords : Thermal Comfort, Lecture Hall (C4) of The Faculty of Engineering University of Ichsan Gorontalo, Thermal Sensation Vote (TSV), Thermal Reception, Thermal Preference.

\begin{abstract}
Abstrak
Kenyamanan termal suatu ruang kuliah diperlukan untuk mendukung proses penerimaan pembelajaran oleh mahasiswa. Penelitian ini bertujuan untuk mengetahui kenyamanan lingkungan termal pada ruang kuliah (C4) Fakultas Teknik Universitas Ichsan Gorontalo dengan menggunakan sistem penghawaan buatan (AC). Kuisioner dibagikan kepada 30 mahasiswa Teknik Arsitektur dengan menggunakan sensasi termal ASHRAE, penerimaan kondisi termal serta preferensi termal. Bersamaan dengan itu dilakukan pengukuran lapangan untuk mengetahui temperatur udara (Ta), kelembaban relatif (RH), Mean Radiant Temperature (MRT) dan kecepatan udara (Va). Hasil penelitian menunjukkan bahwa 50\% mahasiswa memilih agak dingin pada sensasi termalnya sedangkan $97 \%$ dapat menerima keadaan termal ruang, dan hampir $70 \%$ mahasiswa tidak menginginkan perubahan kondisi termal pada ruangan tersebut.
\end{abstract}

Kata kunci: Kenyamanan termal, Ruang kuliah (C4) Fakultas Teknik Universitas Ichsan Gorontalo, Thermal sensation vote (TSV), Penerimaan termal, Preferensi termal.

\section{PENDAHULUAN}

Gorontalo merupakan kota yang memiliki temperatur yang cukup tinggi mencapai $33,5^{\circ} \mathrm{C}$ dengan kelembaban relatif yang cukup tinggi pula mencapai $93,7 \%$ [1]. Keadaan letak astronomis kota Gorontalo yang terletak dekat dengan garis khatulistiwa yaitu berkisar antara $00^{\circ} 28^{\prime} 17^{\prime \prime}-00^{\circ} 35^{\prime} 56^{\prime \prime} \mathrm{LU}$ dan $122^{\circ} 59^{\prime} 44^{\prime \prime}-123^{\circ} 05^{\prime}$ 59" BT, turut mendukung terciptanya temperatur udara yang panas di daerah kota Gorontalo. Kondisi lingkungan termal yang panas dapat mempengaruhi kenyamanan manusia dalam 
melakukan segala hal dalam kehidupannya [2] termasuk dalam aktivitas perkuliahan

Kondisi ruang kelas merupakan salah satu penentu kualitas pembelajaran mahasiswa. Untuk itu, dibutuhkan ruang kelas nyaman dari segi kebersihan, audial, visual maupun secara termal. Sebuah studi lama menyebutkan bahwa ada pengaruh dari kualitas termal suatu ruangan kelas dengan prestasi belajar siswa atau mahasiswa (Pepler \& Warner, 1968) [3]. Beberapa studi belakangan ini juga menunjukkan adanya hubungan positif antara kualitas ruangan (termasuk di dalamnya kondisi termal) dengan prestasi siswa (Mendell \& Heath, 2005; Sensharma, Woods, \& Goodwin, 1998) [3]. Karena itu kenyamanan termal menjadi suatu hal yang sangat penting diperhatikan pada ruang kuliah, demi tercapainya proses belajar yang kondusif dan memberi hasil yang memuaskan bagi peserta didik (mahasiswa).

Penelitian ini bertujuan untuk mengetahui kenyamanan lingkungan termal ruang kuliah (C4) Fakultas Teknik Universitas Ichsan Gorontalo, dengan penggunaan penghawaan alami berupa bukaan jendela dan ventilasi yang terletak hanya pada satu sisi dinding yaitu area dinding belakang ruang.

\section{METODOLOGI}

Penelitian ini dilakukan dengan metode survey analitis, merupakan bagian dari metode penelitian kuantitatif. Data kuantitatif yang diukur berupa data dari pendekatan heat balance oleh Fanger yaitu data lingkungan fisik indoor. Pendekatan kuantitatif digunakan dengan membagikan kuisioner tentang kenyamanan termal adaptif individu yang nantinya dikorelasikan dengan hasil pengukuran yang hasilnya akan dijabarkan dalam bentuk tabel dan grafik dan dijelaskan secara deskriptif [4].

\section{Lokasi dan Waktu Penelitian}

Penelitian ini dilakukan pada siang hari yaitu pada saat proses belajar mengajar sedang berlangsung sekitar pukul 11.00 WITA di Ruang Kuliah (C4) Fakultas Teknik Universitas Ichsan Gorontalo yang terletak di
Jalan Achmad Nadjamuddin nomor 11, Kota Gorontalo.

\section{Instrumen Penelitian}

Alat pengukuran untuk data primer yang digunakan adalah:

1) Alat sketsa, alat perekam visual berupa kamera; Merk: Canon seri 5000, untuk menjelaskan kondisi obyek penelitian.

2) Termokopel merupakan alat untuk mengukur suhu ruangan, Termocoupel Meter Type Double Ways VA 8060, dengan tampilan digital.

3) Anemometer Hot Wire, merupakan alat pengukur pergerakan udara yang sangat lemah/perlahan, merk Lutron AM.4204.

4) Temperature and Humidity Meter merupakan alat untuk mengukur temperatur lingkungan dan kelembaban lingkungan, merk Krisbow KW06-797.

5) Heat Stress WBTG untuk mengukur $T_{\text {globe }}$ ruang untuk mengetahui Mean Radiant Temperatur (MRT).

6) Personal Komputer (PC)

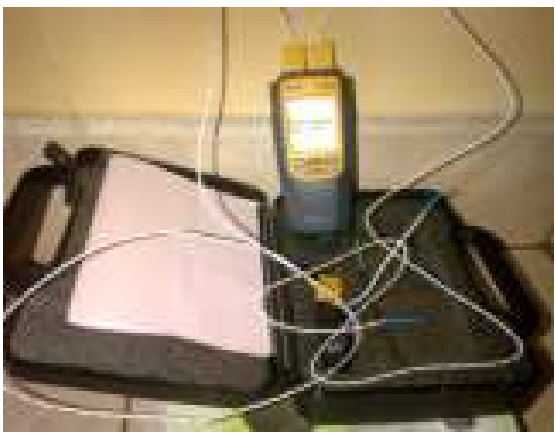

Gambar 1. Alat Ukur Termocoupel Meter Type Double Ways VA 8060

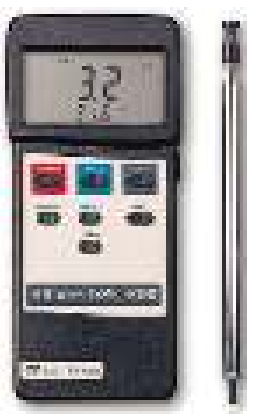

Gambar 2. Alat Ukur Anemometer Hot WireMerk, Lutron AM-4204 


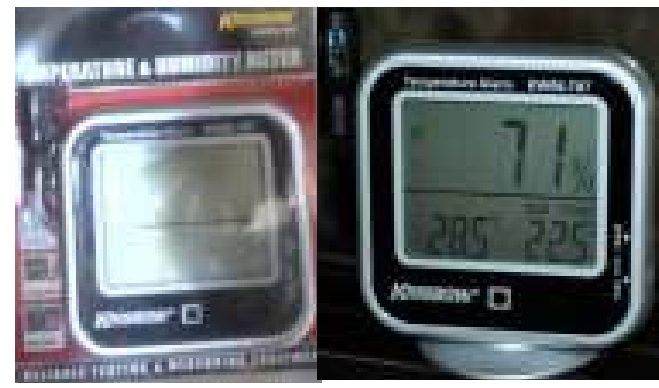

Gambar 3. Alat Ukur Temperatur dan Kelembaban, merk Krisbow type KW06-797

\section{Pengumpulan Data}

a. Pengukuran Lingkungan Fisik

Melakukan pengukuran lingkungan baik di dalam maupun di luar ruangan dengan mengukur temperatur bola kering $\mathrm{Tdb}$, temperatur globe $\mathrm{T}_{\text {globe, }}$ kecepatan angin $\mathrm{Va}$, dan kelembaban RH.

\section{b. Kuesioner}

Terhadap responden tersebut diberikan kuesioner terkait sensasi termal (TSV), penerimaan kondisi termal dan preferensi kondisi termal.

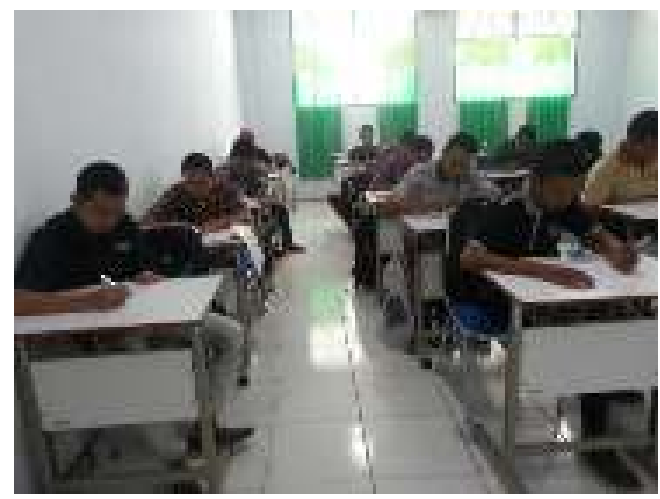

Gambar 4. Pengukuran di Ruang Kuliah (C4) Arsitektur Unisan

\section{Analisis data}

Berdasarkan kuesioner dan data pengukuran, maka dilakukan analisis sensasi termal (TSV), penerimaan dan preferensi termal. Analisis sensasi termal dilakukan terhadap hasil jawaban kuisioner terkait pertanyaan mengenai sensasi termal dengan skala ASHRAE. Analisis penerimaan kondisi termal dilakukan terhadap hasil jawaban kuesioner penerimaan kondisi termal. Analisis preferensi kondisi termal dilakukan dengan menganalisis hasil kesan termal terkait kuesioner preferensi kondisi termal.

\section{HASIL DAN PEMBAHASAN}

Hasil pengukuran menunjukkan bahwa ruang Kuliah (C4) Fakultas Teknik Universitas Ichsan Gorontalo dengan penghawaan buatan pada saat dilakukan pengukuran lingkungan termal adalah diatas rata-rata standar kenyamanan orang Indonesia yang berkisar antara $22,8^{\circ} \mathrm{C}-25,6^{\circ} \mathrm{C}[5]$. Temperatur ruang menunjukkan angka $29,7^{\circ} \mathrm{C}$, padahal ruangan telah difasilitasi dengan sistem penghawaan buatan (AC). Hal ini dapat disebabkan oleh adanya panas dari cahaya lampu yang dapat meningkatkan suhu ruang. Adapaun $\mathrm{T}_{\text {globe }}$ menunjukkan angka $29^{\circ} \mathrm{C}$. Adapun kelembaban relatif cukup rendah $34 \%$ serta kecepatan udara yang cukup rendah pula yaitu $0,05 \mathrm{~m} / \mathrm{s}$.

\section{Thermal Sensation Vote (TSV)}

Hasil jawaban kuisioner 32 orang mahasiswa, menunjukkan bahwa sebanyak 8 responden $(25 \%)$ dalam hal ini mahasiswa arsitektur memilih netral pada sensasi termalnya, 6 responden (18,75\%) memilih sensasi termal agak hangat, dan $50 \%$ atau sebanyak 16 responden menjatuhkan pilihannya pada sensasi termal agak dingin. Adapun sebanyak 1 responden (3,13\%) memilih sensasi termal hangat, dan 1 orang responden $(3,13 \%)$ memilih sensasi termal dingin.

\section{Penerimaan Kondisi Termal}

Hasil penelitian menunjukkan bahwa $97 \%$ atau 31 responden dapat menerima kondisi termal walaupun pada saat pengukuran menunjukkan temperatur yang cukup tinggi yaitu hampir mencapai angka $30^{\circ} \mathrm{C}$ serta pemilihan sensasi termal yang hampir $50 \%$ memilih agak dingin. Hal ini dapat dikarenakan oleh responden tersebut dalam hal ini mahasiswa telah beradaptasi dengan kondisi termal yang ada. Apalagi temperatur di kota Gorontalo yang cukup tinggi juga. 
Menariknya, terdapat 1 responden yang tidak dapat menerima kondisi termal yang ada dan menginginkan agar ruangan menjadi lebih hangat. Adapun mahasiswa tersebut berasal dari salah satu kota di provinsi Papua dimana temperatur di kota tersebut lebih tinggi dari temperatur udara di kota Gorontalo.

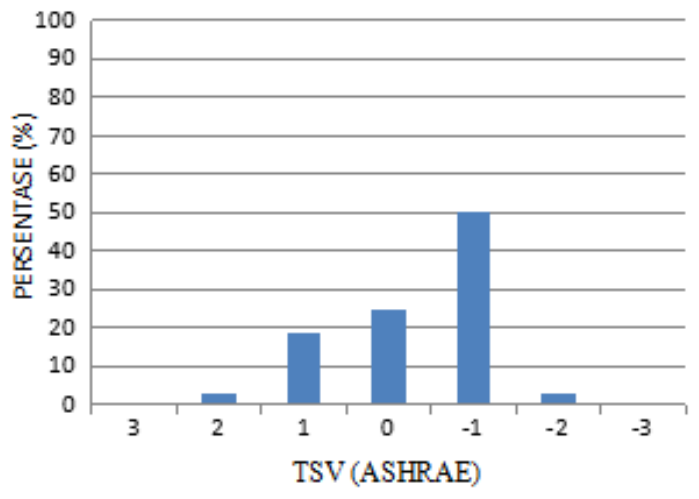

Gambar 5. Thermal Sensation Vote (TSV)

\section{Preferensi Termal}

Untuk preferensi termal, hanya 10 responden $(31,25 \%)$ yang tidak menginginkan agar ruangan kuliah menjadi lebih sejuk, sedangkan sebanyak 21 responden $(65,63 \%)$ menginginkan agar kondisi ruangan tetap/tidak berubah. Adapun 1 responden asal provinsi Papua menginginkan agar ruangan menjadi lebih hangat.

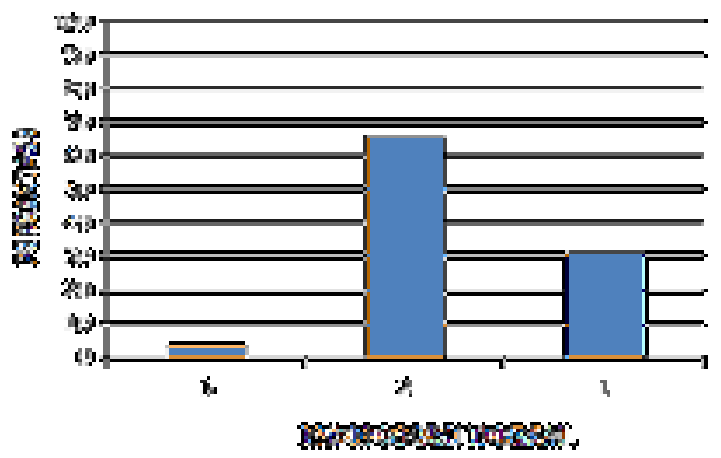

Gambar 6. Preferensi Termal

\section{KESIMPULAN}

Ruang kuliah (C4) Fakultas Teknik Universitas Ichsan Gorontalo masih menunjukkan angka temperatur udara yang cukup tinggi dibandingkan dengan standar kenyamanan orang Indonesia dengan nyaman optimal $22,8^{\circ} \mathrm{C}-25,6^{\circ} \mathrm{C} \quad$ [5]. Walaupun demikian, akibat faktor adaptasi terhadap temperatur udara kota yang tinggi, sehingga mahasiswa masih dapat menerima kondisi lingkungan termal tersebut, terbukti dengan kebanyakan mahasiswa memilih agak dingin pada sensasi termalnya.

\section{SARAN}

Objek serta waktu penelitian yang terbatas, mengakibatkan perlunya penelitian yang lebih lanjut agar hasil yang didapatkan dapat benar-benar akurat.

\section{DAFTAR PUSTAKA}

[1] BPS Kota Gorontalo. 2013.

[2] Nobert Lechner. "Heating, Cooling, Lighting". Jakarta: PT. Raja Grafindo Persada, 2007.

[3] Muhammad Tayeb, Ramli Rahim, Baharuddin Hamzah. "Pengaruh luasan Bukaan Terhadap kenyamanan Termal Ruang kelas Siswa Pada Bangunan SD Negeri Sudirman 1 Kota Makassar". Simposium Nasional RAPI XV2016 FT UMS, 2016.

[4] Indah Sari Zulfiana. "Kenyamanan Termal Adaptif Rumah Tinggal di Kota TimikaPapua”. Tesis Pasca Sarjana Teknik Arsitektur Universitas Hasanuddin, 2015.

[5] Sally Septiana Napitupulu. "Pengaruh Orientasi Bangunan dan Kecepatan Angin terhadap Bentuk dan Dimensi Filter Pada Fasad Bangunan Rumah Susun". E-Journal Graduate Unpar, Vol. 1, N0.2 ISSN:2355-4274, 2014. 